\title{
Application of Video Based Learning and other digital materials for online classes in Japan
}

\author{
Adam L. Miller \\ Aichi Shukutoku University, almiller@asu.aasa.ac.jp
}

\begin{abstract}
The paper aims to examine the use of multimedia and Video Based Learning (VBL) in classes in Japanese universities, which may have moved from face-to-face to online platforms. It will also attempt to investigate if there are any tangible benefits to these materials/platforms being used, and if their continued use (after classes return to the classroom) may be advantageous to teachers or their students.
\end{abstract}

Keywords: online learning, VBL, 4IR, higher education, Japanese higher education.

\section{Introduction}

The COVID-19 pandemic has forced many higher education institutes around the world to change their teaching methods, with the World Health Organization stating that as of July $4^{\text {th }} 2021$, there were 183,198,019 confirmed cases of COVID-19 worldwide and 3,971,687 confirmed deaths (WHO, 2021). Cases may be comparably low in Japan in regards to many other developed nations, with 814,533 confirmed cases and 14,933 deaths as of July 8th (NHK, 2021). Nonetheless, protocols have been put in place in the hope of making learning environments safer.

These adaptations could be assigned to one of just two categories; altering physical classrooms or moving lessons to a digital platform. For classes that remained "in-person" (hereon referred to as face-to-face lessons), a variety of measures have been encouraged, such as wearing masks and/or face shields, ensuring ventilation is optimal, having rubbing alcohol readily available and encouraging social distance. The alternative approach saw classes being shifted online, either synchronous (hereon referred to as "real-time lessons"), or asynchronous (hereon referred to as "on-demand lessons"). Real-time lessons saw educators communicating with their students via voice or video calls, oftentimes using an online video conferencing application (such as Zoom, Google Meet, Microsoft Teams etc.). On-demand classes however involved students downloading materials and activities, and completing them before a designated deadline. These materials may be uploaded to the university's own network, or a third-party site, such as Microsoft Teams, Google Classroom or Moodle for example.

The aim of this case study is to look at examples of teachers altering their syllabi to better fit the demand of online lessons, be them real-time or on-demand. The paper aims to have a particular focus on their use of multimedia and modern technologies. To gain an in-depth insight,

This Open Access article is published under a Creative Commons Attribution Non-Commercial 4.0 International License (http://creativecommons.org/licenses/by-nc/4.0/), which permits non-commercial re-use, distribution, and reproduction in any medium, provided the original work is properly cited. For citation use the DOI. For commercial re-use, please contact editor@rupkatha.com. 
two senior tutors (at two separate, reputable private universities) in Nagoya City, Japan were interviewed. Both utilized multimedia, Video Based Learning (VBL) and readily available software to create interactive and accessible classes.

The teachers were interviewed individually and were in no way influenced by each other's answers. To compound their responses, a group of $1^{\text {st }}$ and $2^{\text {nd }}$ year University students were asked to fill in a simple, anonymous survey (see Appendix 1 for survey and results), in the hope of gaining a better idea of students' preferences in regards to teaching style and the inclusion of multimedia. Furthermore, the simple questionnaire presented to the students presented the potential to see if students' views and opinions were in line with the approaches and thoughts put forward by the teachers interviewed.

\section{Methodology}

Three days prior to their respective interview, each interviewee was sent a copy of the questions they were to be asked (see Appendix 2). This allowed them to do any research or gather any materials they may have felt were necessary. It was also the hope it would avoid them feeling "caught-out" by the questions, or unable to answer them. Furthermore, if they thought any of the questions were inappropriate or irrelevant, they had ample time to let me know. I also informed them that while I would attempt to ask each question on the list given to them, I may deviate a little if any interesting tangents presented themselves. While this may have compromised the structure of the interview, the potential reward of exploring a topic I had failed to consider, or diving further in to the expertise of the teachers, made this a favourable risk that had the potential to offer further insight.

The interviews were conducted on Zoom, both for convenience and to avoid any discomfort the interviewees may have felt meeting in person, as a state of emergency was still in effect in Aichi Prefecture at the time of the interview [3]. The state of emergency did not necessarily prohibit our meeting, but as it was a risk that was easily avoidable, our meeting on Zoom seemed like a sensible choice.

The Zoom calls lasted 18 minutes and 23 minutes respectively. The videos were saved and through the use of Adobe Premier Pro, a title card was added. No other editing occurred and the interview was published without otherwise being altered in any way. The video was then uploaded as an "Unlisted" video on YouTube, increasing its accessibility for research purposes, while still protecting the privacy of the interviewees. The videos included automatically generated Closed Captions, which were checked for accuracy. These Closed Captions were then downloaded and edited into a Word file, so that they were both easy to read and reflective of the conversation (See Appendix 3).

Conducting the interview online did bring with it the risk of several potential problems, be them technical (slow internet connection, feedback, camera/microphone malfunction), or interpersonal (talking over each other, the conservation failing to flow). Luckily, the technical aspects did not cause any issues, and to avoid a stunted or awkward interview, I, as the interviewer, tried to give the interviewees as much space and time as needed to answer their questions.

While the teachers did not request anonymity, neither their names nor the educational institute at which they work will be mentioned directly in this paper. This approach was taken to 
allow them the confidence to speak freely, without concern for repercussions. While neither of the interviewers spoke disparagingly about their places of work, including their names and the names of the universities of where they work does not appear to add any apparent benefit, so to air on the side of caution, they have been purposefully omitted. They will instead be referred to as "Teacher 1" and "Teacher 2" throughout this paper.

In regards to the questionnaire given to the class of $1^{\text {st }}$ and $2^{\text {nd }}$ year students, it was an anonymous and voluntary survey with just 4 questions. This unobtrusive method was chosen to stay in line with the ethical guidelines of the university these students attend, which declares that class observations can only be conducted after a lengthy application process. As the focus of this study was the methods adopted by teachers and curriculum makers, the overall results should not be hindered by the limitations of this questionnaire, especially as it will be referred to sparingly. The questionnaire was entirely voluntary, and 17 students (out of a potential 21) completed it.

\section{Findings}

Both teachers interviewed stated that they have used VBL and different types of multimedia in their on-demand lessons. While there are a number of drawbacks to preparing such materials, such as technical difficulties and time constraints (which we will explore later in the paper), there are also a number of benefits:

"Learning videos are considered capable of helping both educators and students because they can be listened to repeatedly and contain audio and visual content so that it is expected to be able to help the learning process from home be as concrete at school." (Suryandari \& Singgih, 2021, p.3)

It would be extremely difficult to replicate the learning environment of a classroom, but VBL and multimedia lesson materials can go towards making on-demand lessons more engaging and effective. Not only are videos potentially beneficial for teachers and students alike, institutes may also see a benefit, as creating a single video that can be accessed by a group of students could be less of strain on the platforms and networks involved, with video "being considered capable of delivering material better than modules and reducing the quantity of internet quota usage compared to video conferences." (Suryandari \& Singgih, 2021, p.2)

Both teachers interviewed went through lengthy planning and preparation processes to create engaging lessons, that utilized VBL and other multimedia materials, which seemingly improved the online learning environment for their students, with Teacher 1 stating:

"I run my on-demand classes [so that] my students actually really felt like it was a real class, because [...] I did use a lot of video stuff and I really did make the students seem like they were joining a real class." (Teacher 1, 2021, lines 29-30)

Teacher 1 clearly states that the use of video in her on-demand classes helped elevate the lessons to be closer in efficiency and engagement to a face-to-face class. This supports the claim of Suryandari and Singgih, that through the use of videos, distance learning has the potential to create learning environments that are as "concrete" as face-to-face classes.

The benefits of VBL and multimedia proposed by both Teacher 1, and Suryandari and Singgih are sentiments that are supported by Teacher 2: 
"Students[...] and everybody these days, tend to be more captivated by video than by words[...] Video is attractive for people. Well-made video, that's, you know, kids watch YouTube all the time anyway. It's what they're used to." (Teacher 2, 2021, lines 150-156)

The accessibility of YouTube means it can be integrated into almost any format of learning environment, be it face-to-face, real-time or on-demand. All that is required is an active link, which the students (or teacher) can simply click, and be taken to the relevant video.

These materials are obviously limited to the internet access of the students, and an argument could be made that making YouTube videos an integral part of a lesson may in fact exclude certain students from an optimal learning experience. This is unlikely to be the case in Japan however, as YouTube is a very prevalent platform for the age group most associated with undergraduate studies. A report written in October of 2020 stated "the online video platform YouTube had a penetration rate of close to 94 percent among people aged 13-29 years old in Japan as of January 2020." [3] Choosing a platform that students are "used to" allows for a more seamless approach in integrating materials into a classroom. It also removes the hurdle of students having to master the use of a new platform, as YouTube is more than likely a platform they are already very comfortable with.

As previously mentioned, two of the biggest flaws in teachers creating their own video content is that there are both technical hurdles to overcome and time constraints to consider. Technical issues may include mastering editing software, acquiring and learning to use cameras and microphones, or getting to grips with online platforms. In regards to time constraints, both teachers discussed this problem:

"It was time consuming [...] Because it would be making the PowerPoints, collecting the video clips if I was using [...] the video clips were OK because [...] I usually used things that I had used in past when I was doing face-to-face lectures. But it was the combination of [...] having to fix all of my presentations so that they were more video orientated." (Teacher 1, 2021, Lines 119 - 124)

Here Teacher 1 states that she both adapted existing lesson plans and materials, as well as exploring new approaches to make her classes as rewarding as possible. Teacher 2's approach deviated as he used the learning platform, Moodle, and created the semester's materials ahead of time, which was a large investment of time at the beginning of the process, but allowed for automated grading once all of the planning was completed:

"What I did was I created quizzes, videos, activities for the entire semester, and it was a colossal amount of work up front, so last year in particular I spent months and killing myself preparing all of these materials and [...] then I was able to sit back to a fair degree and let it run on automatic. Which for me, I considered to be an advantage. I like [...] to have everything done and then to just let it play out." (Teacher 2, 2021, Lines 43 - 49)

Whether adapting and updating existing materials like Teacher 1 or creating the entire curriculum for the term like Teacher 2, both approaches involve an initial investment of time by the teachers. But, the rewards of this investment are very clear, in regards to Teacher 1 , she was able to bring her online classes closer to the interactive standard of her face-to-face lessons, and 
5 | Application of Video Based Learning and other digital materials for online classes in Japan

Teacher 2 had the benefit of Moodle having the power to grade a large proportion of his students' work.

The problem of time management is made even more stressful when one considers that these changes may have been made after a shift in teaching methods, brought about by a decision made by the university, based upon the State of Emergency announced in the area. A number of institutes in Japan shifted from face-to-face to online learning during the term, which may have seen a number of tutors having to rearrange a curriculum they had already mapped out. This was seen in the second term of 2020, in which different universities brought some (but not all) of their classes back to the classroom (The Japan Times, 2020).

At the start of 2021, a majority of universities in Japan vowed to return to face-to-face classes, even with concerns over the spread of COVID-19:

"Many universities have switched to face-to-face classes when there is no prospect of controlling the infection because they are concerned about students feeling isolated." (The Mainichi, 2021)

But after just a few weeks, many institutes moved back to online lessons. Both students and teachers had been told to prepare for face-to-face classes, and both had to drastically adapt to these sudden changes.

The universities at which both Teacher 1 and Teacher 2 worked had returned to ondemand classes by the middle of the first term during the 2021 academic year. To alleviate the stress of producing videos on time for a number of courses, but still reaping the rewards of VBL, Teacher 2 explained that he utilized a number of online resources to try and make his resources both more engaging and effective:

"It was fairly easy to find them (materials on YouTube)[...] you have the choice, you can have something very specific that you want to teach and [...] search endlessly for the right material or you can find the right material and extract what is important." (Teacher 2, 2021, Lines 166 - 169)

Here Teacher 2 addresses two teaching approaches that can be used when using existing materials. First is to plan your lesson as normal, and then try and find the right video that slots into what you hope to achieve in your lesson. As the available content on YouTube is so extensive, this may be possible for the vast majority of teachers, but as Teacher 2 alludes to, it can be a very time consuming to do so. The other option is to find interesting materials and then craft your lessons around those. This approach may necessitate the teacher being more flexible when creating their lesson plans, but allows them to draw from a wider range of materials. Although both approaches have potential drawbacks, they too bring with them the benefits of $V B L$, without the burden of having to create the content.

As well as using YouTube as a digital library, from which a plethora of resources can be quickly and easily accessed, it is also a very convenient platform to which the teachers are able to upload their own materials. Creating one's own videos has some very strong benefits, such as the content being tailor made to suit the subject of the lesson, no matter how niche or specific it may be. Furthermore, as the material was created by the teacher, worries about the materials being inappropriate should be alleviated. Furthermore, another potential benefit of recording and 
sharing a class could be that students have the ability to digest the information in their own time, with research having shown that "students found that the videos uploaded by the teachers were fascinating as they can see them again, pause and take notes when needed" (Mishra et al, 2020). While the ability to pause a video to take notes or rewind it in order to rewatch particularly difficult sections in a lesson may seem like basic functions, they have the potential to allow students of varying English fluency to understand what is being addressed in the class. This allows the teachers to explore more complex topics, which the students can digest in their own time.

Teacher 1 actually spoke of the benefits of recording her lessons and uploading them for her students to access when they were able. The scheme was so successful, that a number of her students requested it be continued, even when classes returned to a face-to-face setting:

"My seminar students said "Can you please keep all [..] your [...] lectures as videos and put them up so that we can watch them again even when we go back to face to face?"." (Teacher 1, 2012, Lines 50 - 53)

This is a clear indication that the students found the videos helpful and/or useful to their development. It is also a teaching technique that should not be too difficult to implement in the future, and should not impede on the teachers' ability to teach face-to-face. By acquiring the skills of recording and uploading her classes, Teacher 1 now has access to a new teaching method, a tool that can assist her students in the future.

Besides being a platform to which one can upload their own materials, and being an extensive library of potential classroom materials, Teacher 1 also explained YouTube was a fantastic resource to inspire her to create her own, more professional looking materials:

"I did a lot of watching of [...] educational YouTube videos to see what they do, and see what works and what doesn't work and tried to apply that to my own teaching materials." (Teacher 1, 2021, Lines 157 - 159)

As stated earlier, YouTube has permeated the zeitgeist in Japanese culture, especially amongst the age group most likely to attend university. It stands to reason that there would be a plethora of materials aimed towards this demographic. While much of it may not be useful or suitable, Teacher 1 sought out videos that she felt could enrich her classes. In trying to emulate this quality and approach, Teacher 1 was more likely to create materials that would connect with her students, as she explains:

"If you make something very professional looking they are more likely to pay attention, and [...] actually listen, I think, and if you make it attractive for them then they're more likely to listen." (Teacher 1, 2021 Lines 145 - 148)

The additional step of researching existing videos that are similar in tone, theme or content to what the teacher wishes to create, may exasperate the time consumption problem, and could arguably be an additional step that some may find too wearisome. However, it is a rich vein of ideas that can be mined, and in turn shared with the students, so it stands to reason that Teacher 1 thought of this as a good use of her time and energy.

Teacher 2 indicated that he began the term by using his own videos, but as time went on, he found it much more efficient to spend his time finding suitable materials, instead of creating 
his own. Although the before-mentioned benefits of videos specifically designed for a lesson may be lost, there are some potential benefits to relying on existing materials. First and foremost is the reason stated by both of the teachers interviewed, it is much less time consuming. Creating syllabi for online learning can already by a very difficult and time-consuming process. Finding existing materials however, can potentially be quicker and less stressful, as there is just one simple step i.e. finding the materials. This simplicity seems diametrically opposed to a process of having to produce your own material through planning, recording, editing and publishing your work, each step being potentially very difficult, stressful and plagued with technical issues.

Another huge benefit of using existing materials is that they may seem more professional, a consideration Teacher 1 earlier alluded to, when she watched existing materials to find inspiration to improve her own videos. This quality could manifest itself in two separate ways; firstly, the recording equipment used by professional videographers is likely to be far superior to the equipment most teachers have access to, allowing for better audio and visual quality. This in turn improves the viewing experience for the student.

Another benefit may be that an expert in the field of study is presenting the video, allowing for a more informed opinion. Even if the presenter is no more of an expert than the teacher, merely presenting a different perspective could be extremely beneficial to the students. Instead of merely hearing the opinions of their teacher, the students can listen to a wider variety of people, which could in turn help them gain a more rounded understanding of the topic. Lastly, for EFL or ESL students, there may be an indirect benefit in hearing from another person besides their teacher; it will expose them to a different native speaker. This could mean that the video's presenter is from a different country than the students' teacher, and so speak in a different accent, or it could be much more subtle differences, such as a differing cadence or intonations. Either way, this variety may go towards improving fluency, and familiarizing the students with a wider variety of English speakers.

In exposing the students to a wider variety of English speakers, there is the potential for increased English fluency, as studies have shown:

"Instructors need to expose students to various different accents during the process of learning English. Differences in pronunciation should be highlighted during the learning process. Students should also be encouraged to listen to various different accents outside of the classroom environment." (White et al., 2016, p. 27)

YouTube is such an easily accessible resource, it can be easily incorporated into lessons (both online and face-to-face), but is also an accessible path for independent learning, which the students can access outside of the classroom, and study independently.

As previously discussed, using platforms such as YouTube has another intrinsic benefit, namely it is a platform students are largely familiar with, and can use it without prior training or explanation. This makes it a very easy way to engage with students, and may even encourage them to independently use YouTube as a self-educational tool. Furthermore, even for those unfamiliar with YouTube, the teacher can almost seamlessly incorporate videos into their lessons, while requiring little to no effort on the part of the students. In regards to the approach taken by Teacher 1 , they can send students links, which they simply need to click and (assuming they have 
internet access) will take then directly to relevant video. Teacher 2, who was using the Moodle platform, could embed videos into his lessons, allowing the students to simply push the play button, and they were able to watch the video without even leaving tab that houses the online class. Either option is fast and easy, for both the students and the teachers, and shows that incorporating VBL need not be burdensome, no matter the skillset of the students or the teachers.

\section{Teaching approaches after the pandemic}

Both teachers were also asked for their predictions of how VBL and multimedia may be used in the classroom after all restrictions are lifted. Although both did foresee the trend of using these materials continuing (especially in their own lessons), they each had varying predictions for the future.

Teacher 2 spoke of his pessimism that these approaches will remain in the educational zeitgeist after the pandemic restrictions have been lifted. Not because they will stop being useful, but because many educators have been using them only reluctantly and do not care to keep abreast with the ever-advancing and changing technology.

"The sad reality is that some of the older teachers [...] they're never really going to get it. Some of them [...] are not [...] able to or willing to engage enough with the technology. As [...] people get older, there is a certain reluctance or an inability to learn new technology." (Teacher 2, 2021, Lines 266 - 270)

VBL, multimedia and other technologies connected to the Fourth Industrial Revolution (4IR), are only as powerful as those handling them. If educators do not continue to familiarize themselves with these technologies, and use them to their full potential, not only will they miss a plethora of potential benefits in regards to easing pressure with planning and undertaking syllabi, they will also impede students' exposure to this technology. This in turn may mean students will be less familiar with a technology that could potentially become ubiquitous within the working environment they will be entering after graduation:

"4IR is characterized by widespread advancement in digital technologies. Although the ubiquity of these technological and digital tools is already well documented, their usefulness and effectiveness are not yet clear. If those in possession of these new technologies cannot generate a meaningful use of them, then their spread will have less positive impact." (B. Xing et al., 2018, p.181)

Teacher 1 had similar thoughts in regards to these approaches gaining a widespread foothold in Japanese higher education institutes:

"I think that it's going to take quite a while for that changeover to happen, if it does happen, because [...] our education systems are still dominated by [...] people who are not tech savvy [...] I think the problem is in Japan, unless Japanese students are [...] actually trained to be more computer literate this is not going to become the main [...] or important part [..] of education." (Teacher 1, 2021, Lines 218 - 223)

Here teacher 1 indicates 2 problems that are inherent in the current educational climate in Japan. Firstly, as many of the senior teachers who actually decide what a curriculum should include are not familiar with this technology, this said technology is therefore not being included in many 
9 | Application of Video Based Learning and other digital materials for online classes in Japan

courses, either due to a reluctance to use it or simply ignorance of its existence. This compounds the second problem of students not having the training to become familiar with this technology. This then creates a vicious circle of both students not wanting to engage in a curriculum they may find confusing, and teachers lacking either the ability or drive to teach students these new approaches. As Teacher 1 states, the focus should be on training the students to be able to use these new approaches seamlessly, but perhaps teachers, no matter their familiarity or opinions on this technology, should also be given the same training, to encourage them to integrate these approaches into their lessons.

Being asked to teach online obviously forced many teachers to learn to use new technologies, including learning platforms such as Moodle, Google Classroom or Microsoft Teams. They were also encouraged to incorporate new tools, such as video conferencing, online slideshows or VBL. While for many teachers, this may have been a turbulent and stressful experience, Teacher 1 explains (that for her at least) it was an opportunity to learn as a teacher, and she states that these approaches have "become just such a big part of my vocabulary now." This willingness and enthusiasm to acquire new skills, adapt and grow as a teacher is a mindset many educators strive towards. The transition from face-to-face to online classes (and in some cases back and forth), need not only be seen as a hurdle to clamber over, but an opportunity to acquire new skills, which could be implemented in future classes.

In short, the onus is on the teachers to keep abreast with technological advances and to incorporate them, when possible, into their lessons. This has the potential to help teachers create more engaging lessons, but also has the added benefit of familiarizing students with these technologies, which could be hugely beneficial to them. If students do not familiarize themselves with these digital technologies, they may find themselves at a disadvantage in the competitive jobs market they will be thrust into after graduation. Therefore, it is imperative for all educators, no matter their preference in teaching style, to begin to embrace more digital technology in their classes to holistically teach their students how beneficial they can be.

\section{Student Feedback}

Although a very simple questionnaire, the students' feedback helps triangulate the opinions of both teachers to form a consensus. The questionnaire focused on just two questions, the type of multimedia accompaniments (if any) the students favored, and what style of lesson they preferred. They were also given the space to give feedback, either in English or their native Japanese.

In regards to type of lesson, as both Teacher 1 and 2 had inferred in their interviews, students tended to largely favor face-to-face lessons. A total of $88.9 \%$ picked face-to-face classes, many of them stating the social aspect as their drive to get back to the classroom, with feedback such as, "I want to mee[t] classmate[s]."

Others suggested that the format of a face-to-face lesson is much more effective. "Because I feel I can understand more than the other lesson styles." This suggests that although multimedia and VBL may improve online lessons (as well as face-to-face lessons), there are still many improvements that need to be made to online classes to make them as effective as tradition faceto-face classes. Others spoke of the technical issues in using online classes, in regards to both the fluidity of teaching and the accessibility to integral parts of lessons, such as group work: 
"It's difficult for me to discuss with my friends on online lessons."

Of the remaining $11.1 \%$, all of the students chose on-demand lessons. There was not a single vote for real-time lessons online. One can assume that this is because this method has neither the convenience of on-demand lessons nor the social aspects of face-to-face lessons. But as the questionnaire did not give the students the chance to say why they didn't pick an option, this is just conjecture and should be treated only as this paper's interpretation and not necessarily reflective of the students' opinions.

Most students spoke of the social benefits of face-to-face classes, alluding to the fact that this is an integral part of successful learning environments. This is arguably an aspect of learning that VBL and multimedia materials cannot replace. They may alleviate the stress induced by online learning, or make it more palatable, but it is unlikely to act as a complete replacement. That being said, it does show promise in improving all learning environments, be them face-to-face or some version of online, as in both cases, VBL and multimedia can enrich a lesson and make it more enjoyable for the students.

The students interviewed were using a textbook that included lengthy reading activities. To accompany these reading activities the students were given video recordings of me reading the text, which were uploaded to YouTube as unlisted videos, which could be accessed simply by following an active link. They were also given audio recordings, which were both embedded in PowerPoint slideshows used in class, and also uploaded to Google Classroom as a separate file. In the questionnaire the students were given three options to choose from in regards to how they preferred to approach these reading activities; accompanying videos, audio files or simply reading from the textbook by themselves, without the use of multimedia. Although there was no outright choice (Video 55.6\%, Audio 38.9\%), combined they showed that most students would prefer some sort of multimedia material to assist with the reading activity. Even accounting for there being 2 options for media and only 1 for sans-media, the combined votes for video and audio exceeded the $2 / 3$ majority they held as options, with a combined share of $94.5 \%$.

The results of the questionnaire, whilst limited, did confirm some of the thoughts put forward to the teachers interviewed. Firstly, both teachers suspected that students would prefer face-to-face classes over online, citing social aspects as one of the foremost reasons for this choice. This was echoed in the feedback from the students. Secondly, the students overwhelmingly choosing audio or video materials to accompany reading activities shows that multimedia has the potential to enrich classes, be them online or face-to-face.

\section{Conclusion}

If the initial obstacles of time constraints and limited knowledge of equipment and software can be overcome, VBL and multimedia materials have the ability to enrichen the learning environment, even after the necessity of using these approaches have passed with restrictions brought about by the pandemic. In preparation for the 4IR, and with many instructors being previously unfamiliar with multimedia and online resources, the restrictions of the past year have the tangible benefit of forcing a generation of educators to adapt and learn new skills, which can in turn benefit the next generation of students. 
Software like Zoom and materials found on YouTube have now been normalized in the classroom, and are no longer alien to either the teachers planning a curriculum or the students enrolled in a course. By incorporating these materials, as well as using online resources and teaching platforms, many educators are in a much better position to offer the flexible courses the students of tomorrow will require:

"Blended instruction and optimization of flipped and online courses will make more efficient learning environments that can adapt for diversity in preparation of students. The Future of Education Report at MIT strongly emphasizes the need for leveraging online courses to strengthen the residential education for undergraduates and to also give more flexibility and modularity of courses." (Penprase, 2018, p.219)

Another inherent benefit of more digitally enhanced curriculums is that they have the potential to greatly improve accessibility, which can help reach a wider range of students and prepare them for the inevitable yet unknowable future of the 4IR:

"In the era of $4 \mathrm{IR}$, learning becomes a necessity for humans to compete with machines. Therefore, students (or more precisely people) should be capable of learning and working anywhere, with uninterrupted access to study materials, and keeping their peers within reach." (B. Xing et al., 2018, p.180-181)

Students with sensory or physical disabilities may also find it much easier to access these learning materials if they can do so from their home, but still be assured the courses they are partaking in are both effective and engaging.

In short, while the preparation time may be extensive, the inclusion of new technology, multimedia and VBL, can greatly improve learning environments. This is true in regards to enriching online classes, and bringing them to a higher standard, one which is closer to that of face-to-face lessons. Furthermore, the teaching methods and platforms that teachers have mastered due to necessity during the spread of COVID-19, can continue to be used in the future, if (or when) classes return to a more traditional face-to-face setting. While the speed at which this may happen in Japan is debatable, the benefits such materials bring seem to be well founded, and backed by existing research, teachers and their students.

\section{References}

The Japan Times. (2021). COVID-19 state of emergency begins in Aichi and Fukuoka (last accessed on July $10^{\text {th }}$ 2021: https://www.japantimes.co.jp/news/2021/05/12/national/expanded-virus-emergency/)

The Japan Times (2020). Universities in Chubu returning to face-to-face classes (last accessed on July $10^{\text {th }}$ 2021: https://www.japantimes.co.jp/news/2020/10/09/national/chubu-universities-classescoronavirus/)

The Mainichi. (2021) 70\% of 23 major Japanese universities to increase face-to-face classes: Mainichi survey (last access July $10^{\text {th }} 2021$ : https://mainichi.jp/english/articles/20210426/p2a/00m/0na/024000c) 
Mishra, L Gupta, T. Shree, A (2020). Online teaching-learning in higher education during lockdown period of COVID-19 pandemic. In International Journal of Educational Research Open, Volume 1, 2020, 100012

NHK (2021), Coronavirus, NHK WORLD-JAPAN News (last accessed July 10 2021 : https://www3.nhk.or.jp/nhkworld/en/news/tags/82/)

Penprase, B.E. (2018). The Fourth Industrial Revolution and Higher Education. In N.W. Gleason (Ed) Higher Education in the Era of the Fourth Industrial Revolution. Palgrave Macmillan p. 219

Stastista (2021) Penetration rate of YouTube among people in Japan as of January 2020, by age group. (last accessed July 1oth 2021: https://www.statista.com/statistics/1071780/japan-youtubepenetration-rate-by-age-group/)

White, I.R. Treenate, D. Kiatgungwalgrai, A. Somnuk, R. Chaloemchatvarakorn, K. (2016). The Effects of Accent Familiarity on English as a Foreign Language Students' Word Recognition and Comprehension of the English Language. In UTK Journal Vol 10 No. 2 July - December, 2016, p.27

World Health Organization, Weekly Operational Update on COVID-19, 5 July 2021, Issue No. 62 (last accessed on July 10 th 2021: https://www.who.int/publications/m/item/weekly-operational-updateon-covid-19---5-july-2021)

Xing, B, Marwala L, Marwala T (2018). Adopt Fast, Adapt Quick: Adaptive Approaches in the South African Context. In N.W. Gleason (Ed) Higher Education in the Era of the Fourth Industrial Revolution. Palgrave Macmillan p.180-181

\section{Appendix 1 - Student Questionnaire and Results:}

For full details, please follow the link below:

http://www.sb-publishing.com/wp-content/uploads/2021/09/Student-Feedback.png

\section{Appendix 2 - Questions sent to teachers prior to the interview}

For full details, please follow the link below:

http://www.sb-publishing.com/wp-content/uploads/2021/09/Questions-for-Teachers.png

\section{Appendix 3 - Verbatim transcript of Teacher 1 interview}

For full details, please follow the link below:

http://www.sb-publishing.com/wp-content/uploads/2021/09/Teacher-1-Transcript.pdf

\section{Appendix 4 - Verbatim transcript of Teacher 2 interview}

For full details, please follow the link below:

http://www.sb-publishing.com/wp-content/uploads/2021/09/Teacher-2-transcript.pdf

Adam L. Miller, Aichi Shukutoku University, Department of Global Culture and Communication. 